Check for updates

Cite this: RSC Adv., 2018, 8, 29637

\title{
$\beta$-Escin inhibits the proliferation of osteosarcoma cells via blocking the PI3K/Akt pathway
}

\author{
Minyu Zhu, (D) Jinwei Ying, Chaowei Lin, Yu Wang, Kelun Huang, Yang Zhou \\ and Honglin Teng*
}

$\beta$-Escin exhibits anticancer effects on a panel of established cancer cells. However, the effects of $\beta$-escin on human osteosarcoma (OS) are still unknown. The aim of the present study was to investigate whether $\beta$ escin was effective against OS both in vivo and in vitro. Our results showed that $\beta$-escin induced doseand time-dependent effects against MG-63, OS732, U-2OS, HOS and SAOS-2 cell proliferation. $\beta$-Escin also exhibited excellent anti-proliferative and pro-apoptotic effects in an established OS xenograft model. $\beta$-Escin and cytotoxic drugs, including cisplatin, methotrexate (MTX), doxorubicin (Dox) and ifosfamide (Ifos), synergistically inhibited proliferation of MG-63 and OS732 cells in vitro. Moreover, $\beta$ escin induced apoptotic death, activated caspase-3, caspase- 8 and caspase- 9 , and regulated expression of Bax and $\mathrm{Bcl}-2$ in MG-63 cells. In addition, our results showed that $\beta$-escin treatment reduced expression of p-PI3K, p-Akt and p-mTOR both in MG-63 cells and in an MG-63 xenograft OS model. Interestingly, SC79, which is an Akt activator, inhibited the anti-proliferative effects of $\beta$-escin on MG-63 cells. Taken together, our data support the conclusion that $\beta$-escin effectively inhibits OS proliferation both in vivo and in vitro. The inhibitory effect of $\beta$-escin, at least in part, is due to the inactivation of the PI3K/Akt signalling pathway.

Received 25th April 2018

Accepted 4th August 2018

DOI: $10.1039 / \mathrm{c} 8 \mathrm{ra0} 3578 \mathrm{~d}$

rsc.li/rsc-advances surgery-induced turgidity, and disordered venous reflux..$^{5-7}$ In previous investigations, $\beta$-escin has been reported to possess an anti-arthritic effect, and anti-oedematous and antiinflammatory properties in various disease models. ${ }^{8-11}$ More strikingly, it is widely reported that $\beta$-escin effectively inhibits proliferation of various human cancer cell lines (cholangiocarcinoma, prostate cancer cells, gastric adenocarcinoma, colon adenocarcinoma, lung cancer cells, hepatocellular carcinoma, leukaemia) in vivo and in vitro through multiple signalling pathways. ${ }^{12-19}$ However, whether $\beta$-escin has inhibitory effects on OS is poorly understood. Therefore, to explore the possibility of developing $\beta$-escin as a therapeutic agent, in the present study we investigated its effect on human OS cells.

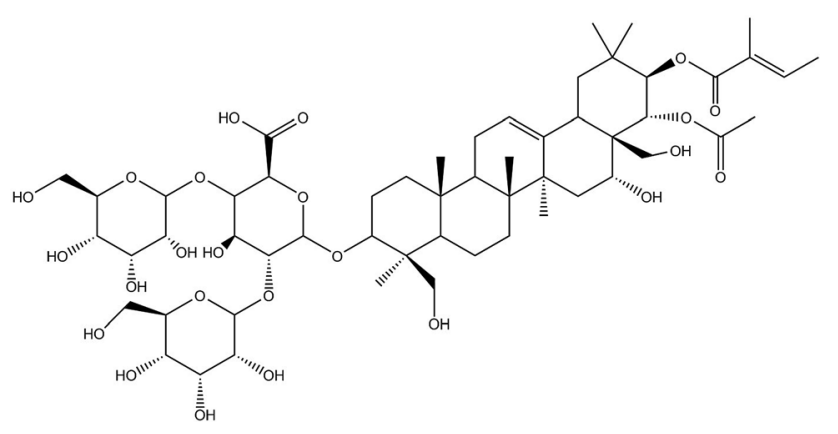

Fig. 1 Chemical structure of $\beta$-escin. Molecular weight: 1131.
Department of Spine Surgery, The First Affiliated Hospital of Wenzhou Medical University, Nanbaixiang Street, Ouhai District, Wenzhou 325000, Zhejiang, China. E-mail:907173102@qq.com; Fax: +8613587688135; Tel: +8613587688135 


\section{Materials and methods}

\section{Cell culture}

Human osteosarcoma cell lines MG-63, OS732, U-2OS, HOS and SAOS-2 were purchased from the Cell Bank of Shanghai Institute of Biochemistry and Cell Biology, Chinese Academy of Sciences (Shanghai, China). The cells were grown in Dulbecco's modified Eagle's medium (DMEM) (Gibco, Invitrogen, Carlsbad, CA, USA) supplemented with 10\% heat-inactivated FBS, $100 \mathrm{U} \mathrm{mL}^{-1}$ penicillin and $100 \mu \mathrm{g} \mathrm{mL}^{-1}$ streptomycin. All cells were cultivated in a humidified atmosphere containing $5 \% \mathrm{CO}_{2}$ at $37{ }^{\circ} \mathrm{C}$. The in vitro study was approved by the Ethics Committee on scientific research of the First Affiliated Hospital of Wenzhou Medical University.

\section{MTT assay}

All cell lines proliferated up to $70-80 \%$ confluence and then seeded in 96-well plates at a density of $1 \times 10^{4}$ cells per well. The cells were treated with $\beta$-escin (Aladdin Chemistry Co, Shanghai, China, 95\% purity) at various concentrations $(0,5$, $10,20,50$ or $100 \mu \mathrm{M})$ for indicated times (24-72 h). Four hours before the end of each incubation period, MTT solution (5 $\mathrm{mg} \mathrm{L}^{-1}$, Sigma-Aldrich, St. Louis, MO, USA) was added to each well and incubated for $4 \mathrm{~h}$ at $37^{\circ} \mathrm{C}$. Then, the cultured medium was replaced with DMSO. The optical density (OD) was recorded at a wavelength of $570 \mathrm{~nm}$ by an enzyme immunoassay analyser (Bio-Rad, Hercules, Calif., USA). To investigate whether the combinations of $\beta$-escin and anti-OS cytotoxic drugs (methotrexate: MTX; doxorubicin: Dox; ifosfamide: Ifos; cisplatin; Sigma-Aldrich, St. Louis, MO, USA) exhibit stronger inhibitory effects on OS proliferation, MG-63 and OS732 cells were cultured in 96-well plates, and then treated with different concentrations of cytotoxic drugs in the presence of $\beta$-escin $(5 \mu \mathrm{M}$ or $10 \mu \mathrm{M})$, or with different concentration of $\beta$-escin in the presence of cytotoxic drugs for $48 \mathrm{~h}$. In addition, to study the effects of protein kinase B (Akt) activator SC79 (purity $>97 \%$, Sigma) on the anti-proliferative action of $\beta$-escin, MG-63 cells were treated with $\beta$-escin in the presence of $20 \mu \mathrm{M} \mathrm{SC79}$ for $48 \mathrm{~h}$. The rate of inhibition of cellular proliferation was calculated as [1-A570 (test)/A570 (control) $] \times 100 \% . \mathrm{IC}_{50}$ was calculated based on nonlinear regression analysis of survival curves (SPSS software, version 13.0, Chicago, IL, USA). All data were collected from three independent experiments.

\section{Apoptosis assay}

MG-63 cells were maintained in the medium containing $\beta$-escin $(2.5-10 \mu \mathrm{M})$ for $48 \mathrm{~h}$. Then, the cells were harvested and washed twice with PBS and re-suspended in $500 \mu \mathrm{L}$ binding buffer. The cells were stained with Annexin V-fluorescein isothiocyanate (20 $\mu \mathrm{g} \mathrm{mL}{ }^{-1}$, FITC, $5 \mu \mathrm{L}$, Life Technologies, Waltham, MA, USA) and propidium iodide (PI) $\left(50 \mu \mathrm{g} \mathrm{mL} \mathrm{m}^{-1}, 5 \mu \mathrm{L}\right.$, Life Technologies, Waltham, MA, USA) for $20 \mathrm{~min}$. The apoptotic rate of MG-63 cells was analysed by flow cytometry using a BD fluorescence activated cell sorting (FACS) flow cytometer (BD Biosciences, USA).
The apoptotic cells in the tumour tissue were detected using terminal deoxynucleotidyl transferase dUTP nick end labelling (TUNEL) assay according to the manufacturer's instructions (Promega, Madison, WI, USA). For nuclear staining, 4',6diamidino-2-phenylindole (DAPI) was used. TUNEL-positive and DAPI-positive staining was visualized in a confocal laser scanning microscope (SP8, Leica Microsystems, Germany). The apoptotic index was calculated as a ratio of an average percentage of positive nuclei, including apoptotic bodies, to a total number of nuclei from five random observation fields at $400 \times$ magnification.

\section{Caspase activity assay}

Caspase-3, caspase- 8 and caspase- 9 activities were detected by a commercial caspase assay kit according to the manufacturer's instruction ( $R \& D$ systems, Minneapolis, MN). To investigate the effect of $\beta$-escin on caspase activation, MG-63 cells $\left(1 \times 10^{6}\right.$ cells per $\mathrm{mL}$ ) received $\beta$-escin treatment $(2.5,5.0,10.0 \mu \mathrm{M})$ for $48 \mathrm{~h}$. Then, the supernatant of lysed cells was added to the reaction mixture containing dithiothreitol and caspase substrates (for caspase-8, caspase-9 and caspase-3), and the mixture was incubated for $1 \mathrm{~h}$ at $37^{\circ} \mathrm{C}$. Finally, the chromophore absorbance was measured and recorded at $405 \mathrm{~nm}$. The data are shown as the fold-changes relative to control.

\section{Western blot analysis}

MG-63 cells were harvested and homogenized in an ice-cold cell lysis buffer (Bio-Rad, Hercules, CA, USA). Cellular lysates were centrifuged at $12000 \times g$ for $30 \mathrm{~min}$ to separate the supernatant. The protein extraction from the tumour tissues was performed in the same way. A bicinchoninic acid protein assay kit (Pierce, Rockford, IL, USA) was used to determine the total protein concentration. Then, equal amounts of total proteins were separated on $12 \%$ sodium dodecyl sulfate-polyacrylamide gels and transferred to polyvinylidene difluoride membranes (Millipore Corporation, Billerica, MA, USA). The membranes were blocked with $5 \%$ skimmed milk for $2 \mathrm{~h}$ and then probed with specific primary antibodies against Bax, Bcl-2, phosphatidyl inositol 3-kinase (PI3K), p-PI3K, Akt, p-Akt, mammalian target of rapamycin (mTOR) and p-mTOR (Abcam, Cambridge, UK) at $4{ }^{\circ} \mathrm{C}$ overnight. After washing three times, the membranes were further incubated with secondary antibodies coupled to horseradish peroxidase. The blots were visualized using electrochemiluminescence reagent (Millipore, Bedford, MA, USA). $\beta$-actin was used for normalization.

\section{In vivo tumour model}

The animal study was carried out according to the U.K. Animals (Scientific Procedures) Act, 1986 and associated guidelines and approved by the Ethics Commission of Wenzhou Medical University. Male Balb/c nude mice aged 6 weeks (Model Animal Research Center of Nanjing University, Nanjing, China) were subcutaneously injected into left side with MG-63 cells $\left(5 \times 10^{6}\right.$ cells). When the tumours reached a size of approximately 150 $\mathrm{mm}^{3}$ (20 days after transplantation), mice were treated with $\beta$ escin $\left(5 \mathrm{mg} \mathrm{kg}^{-1}, 10 \mathrm{mg} \mathrm{kg}^{-1}\right)$ by daily oral administration for 3 
weeks. The tumour volume during treatment was determined at an interval of two days by caliper measurement $[V=1 / 2 \times(L \times$ $\left.\left.W^{2}\right)\right]$. Additionally, the tumour tissues were weighted at the end of study.

\section{Immunohistochemistry}

The tumour tissues were removed at the end of study, and $5 \mu \mathrm{m}$ thick sections of paraffin-embedded, formalin-fixed tumour tissues were stained. In brief, the sections were dewaxed with xylene and hydrated in decreasing concentrations of ethanol. Endogen peroxidase activity was quenched using $3 \% \mathrm{H}_{2} \mathrm{O}_{2}$ (MSDS88597, Sigma) in absolute methanol for $20 \mathrm{~min}$ at room temperature. Sections were then blocked for $1 \mathrm{~h}$ using a Histostain ${ }^{\text {TM}}$-SP Kit (SP9002, ZSGB Biotechnology Co. LTD, Beijing, China; https://www.zsbio.com/product/SPN-9002). The p-PI3K and p-Akt staining was performed according to the manufacturer's instruction (ab182651, ab81283, Abcam, Cambridge, UK). After washing with TBS solution (Tris $10 \mathrm{mM}, \mathrm{NaCl} 0.15 \mathrm{M}$, $\mathrm{pH}$ 7.5), localization of the antigen-antibody complexes was performed by adding diaminobenzidine (D3939, Sigma).

\section{Statistical analysis}

All experiments were repeated a minimum of three times. Data were presented as the mean $(\mathrm{M}) \pm$ standard deviation (SD). For analysis of difference between two groups, Student's $t$ test (SPSS software, version 13.0, Chicago, IL, USA) was performed. A $P$ value less than 0.05 was considered statistically significant.

\section{Results}

\section{$\beta$-Escin inhibits the proliferation of OS cells in vitro}

Cytotoxic effects of $\beta$-escin on MG-63, OS732, U-2OS, HOS and SAOS- 2 cells were investigated by MTT. $\beta$-Escin showed the dose- and time-dependent proliferation inhibition effects on all OS cells (Fig. 2A-E, $P<0.01$ ). The OS732 and MG-63 cells were more sensitive to $\beta$-escin treatment, whereas HOS \& SAOS-2
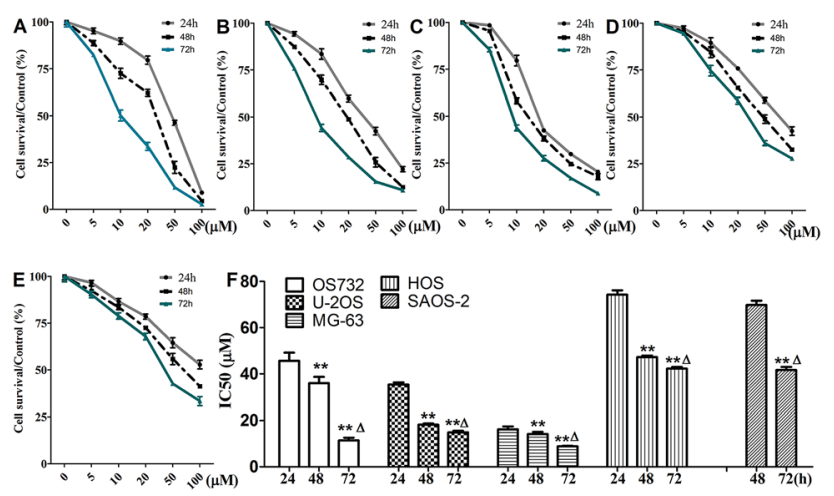

Fig. 2 Viability of OS cells following treatment with $\beta$-escin. OS732 (A), U-2OS (B), MG-63 (C), HOS (D) and SAOS-2 (E) cells were treated with $\beta$-escin $(0,5,10,20,50$ or $100 \mu \mathrm{M})$ for the indicated time. The cell viability was evaluated by $M T T$, and $I C_{50}$ values (F) were calculated based on nonlinear regression analysis of survival curves. Data were collected from three independent experiments. ${ }^{* *} P<0.01 \mathrm{vs}$. the $24 \mathrm{~h}$ group; ${ }^{\Delta} P<0.01$ vs. the $48 \mathrm{~h}$ group. exhibited less response (Fig. 2F). These data indicate that $\beta$ escin effectively reduces the proliferation of OS cells.

\section{$\beta$-Escin and cytotoxic drugs synergistically inhibit OS cell proliferation in vitro}

Based on the results showed in Fig. 2, we found $\beta$-escin exhibited stronger inhibitory effects on proliferation of MG-63 and OS732 cells than the other cell lines. Therefore, MG-63 and OS732 cells were preferentially used to evaluate antiproliferative effects of $\beta$-escin with anti-OS cytotoxic drugs together. Cisplatin, MTX, Dox and Ifos are commonly used antiOS drugs. As seen in Fig. 3A-D, $\beta$-escin ( 5 or $10 \mu \mathrm{M})$ significantly reduced $\mathrm{IC}_{50}$ values of cisplatin, MTX, Dox and Ifos $(P<0.01)$. For example, $\beta$-escin $(5 \mu \mathrm{M})$ decreased $\mathrm{IC}_{50}$ value of cisplatin from $31.7 \mu \mathrm{M}$ to $18.9 \mu \mathrm{M}$, decreased $\mathrm{IC}_{50}$ value of MTX from 3.13
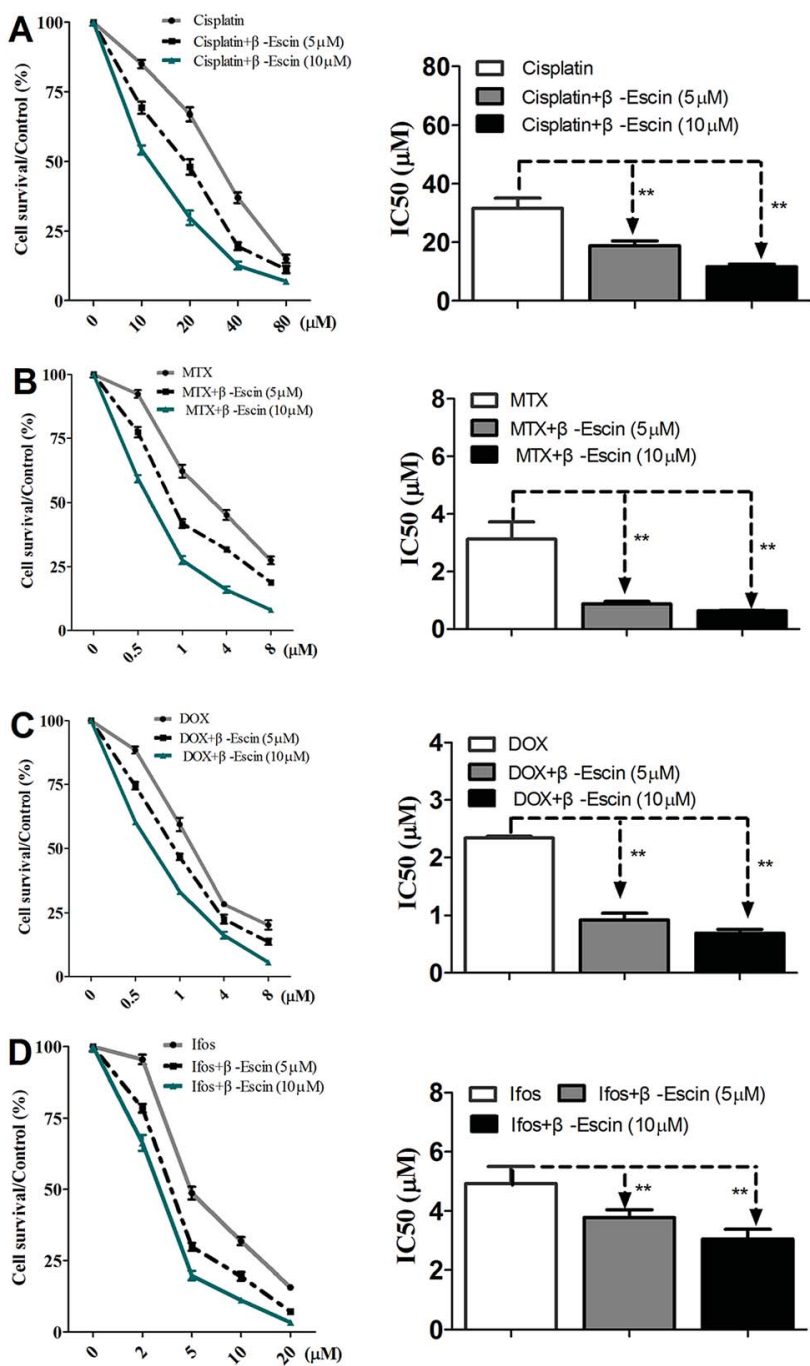

Fig. 3 Effects of $\beta$-escin on cytotoxic drug-induced inhibition of proliferation of MG-63 cells in vitro. MG-63 cells were treated with cisplatin (A), MTX (B), Dox (C) and Ifos (D) in the presence of $\beta$-escin (5 $\mu \mathrm{M}$ or $10 \mu \mathrm{M})$ for the indicated time, and then the cells viability was measured by MTT. Data are presented as the mean $(M) \pm$ standard deviation (SD), and the results were collected from three independent experiments. ${ }^{* *} P<0.01$ vs. the chemotherapeutic drug only group. 
A
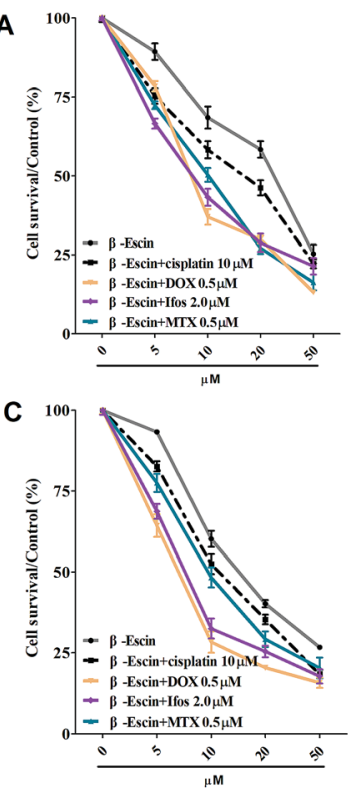

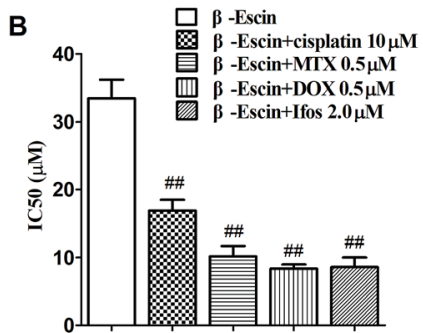

D

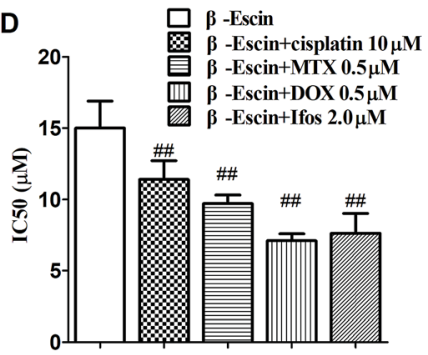

Fig. 4 Effects of cytotoxic drugs on $\beta$-escin-induced inhibition of proliferation of OS732 and MG-63 cells in vitro. OS732 (or MG-63) cells were treated with $\beta$-escin in the presence of cytotoxic drugs (cisplatin, MTX, Dox or Ifos) for the indicated time, and the cell viability was measured by MTT. The OS732 cell survival curves are shown in (A), and the $I C_{50}$ values of $\beta$-escin in the presence of cytotoxic drugs are shown in (B). The curves for MG-63 cells are shown in (C), and the $I C_{50}$ values of $\beta$-escin in the presence of cytotoxic drugs are shown in (D). Data are presented as the mean $(M) \pm$ standard deviation (SD), and the results were collected from three independent experiments. ${ }^{\# \#} P<0.01 \mathrm{vs}$. the $\beta$-escin only group.

$\mu \mathrm{M}$ to $0.88 \mu \mathrm{M}$, and reduced $\mathrm{IC}_{50}$ value of Ifos from $4.92 \mu \mathrm{M}$ to $3.78 \mu \mathrm{M}$. Moreover, it should be noted that a combined use of reduced concentration of cytotoxic drugs and $\beta$-escin could maintain their therapeutic effects. For instance, a combined therapy with cisplatin $(10 \mu \mathrm{M})$ and $\beta$-escin $(5 \mu \mathrm{M})$ showed the same inhibitory effect as with cisplatin $(20 \mu \mathrm{M})$ only. OS cells received a combined therapy with $\mathrm{MTX}(0.5 \mu \mathrm{M})$ and $\beta$-escin $(10$ $\mu \mathrm{M})$ showed the same survival rate $(59.2 \%$ vs. $62.1 \%, P>0.05)$ as cells received MTX $(1 \mu \mathrm{M})$. Moreover, as seen in Fig. $4 \mathrm{~A}-\mathrm{D}$, the cytotoxic drugs studied here significantly reduced $\mathrm{IC}_{50}$ value of $\beta$-escin when treating MG-63 and OS732 cells. These data suggest that $\beta$-escin and anti-OS cytotoxic drugs synergistically inhibit proliferation of human OS cells.

\section{$\beta$-Escin induces apoptosis of MG-63 cells}

As shown in Fig. 5, following treatment with $\beta$-escin $(2.5 \mu \mathrm{M}, 5.0$ $\mu \mathrm{M}$ or $10.0 \mu \mathrm{M})$, the earlier and late apoptosis rates of MG-63 cells were both increased $(P<0.01)$. Our results suggest that $\beta$-escin induces apoptotic death in the MG-63 cells.

\section{$\beta$-Escin induces activation of caspase-3, caspase-8 and caspase-9 in MG-63 cells}

As shown in Fig. 6, caspase-3 in $\beta$-escin pre-treated MG-63 cells was remarkably activated $(P<0.01)$. Moreover, caspase- 8 and caspase-9 were both activated by the treatment with $\beta$-escin $(P<$ 0.01). These results indicate that the inhibitory effect of $\beta$-escin
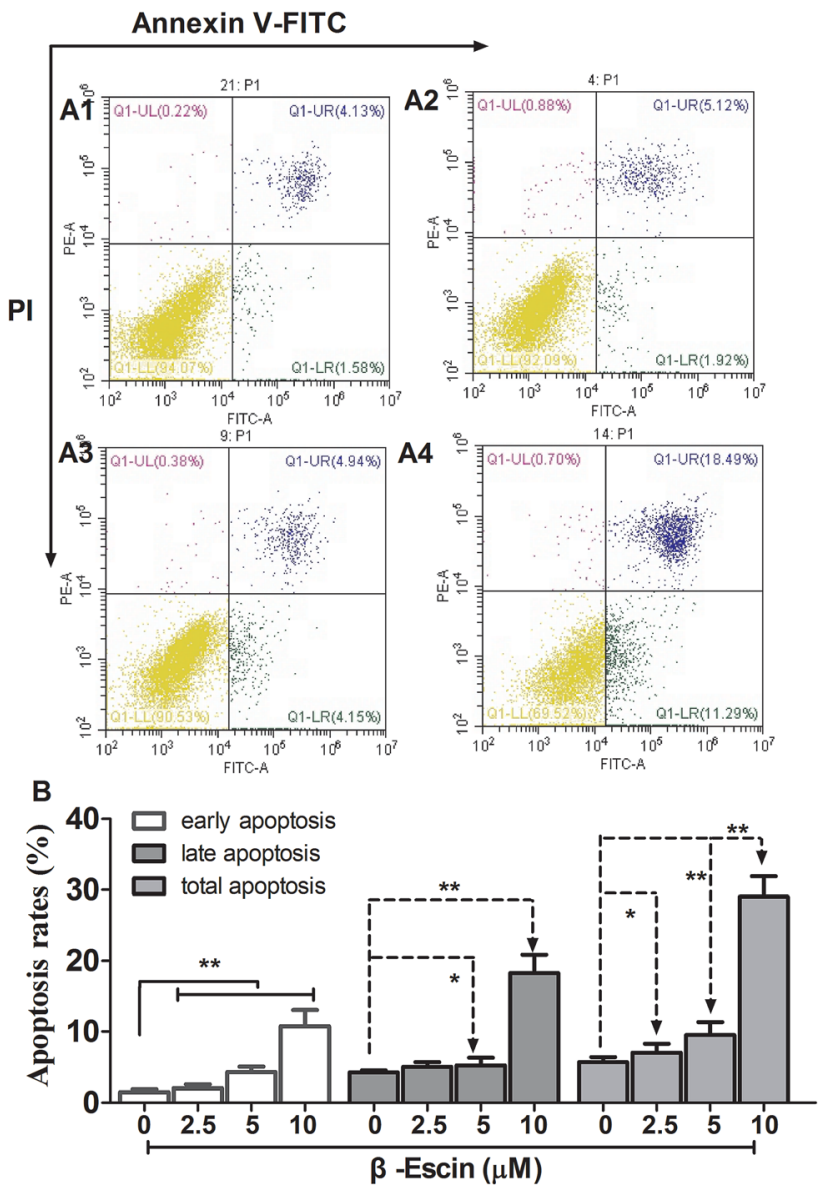

Fig. 5 Apoptosis of MG-63 cells following treatment with $\beta$-escin. MG-63 cells were treated with $\beta$-escin $(2.5,5$ or $10 \mu \mathrm{M})$ for $48 \mathrm{~h}$, and then double-stained by Annexin V/FITC, and analysed by flow cytometry. Representative images are shown in A1 $(0 \mu \mathrm{M}), \mathrm{A} 2(2.5 \mu \mathrm{M})$, A3 $(5 \mu \mathrm{M})$ and $A 4(10 \mu \mathrm{M})$. The apoptotic rates of MG-63 cells treated with $\beta$-escin are shown in (B). Data were collected from three independent experiments. ${ }^{*} P<0.01$ vs. the A1 group.

on cell proliferation was mediated through activation of caspase activity. It is proposed that $\beta$-escin triggers both the extrinsic and intrinsic apoptotic pathways in MG-63 cells.

\section{$\beta$-Escin down-regulates expression of apoptosis-related proteins}

As shown in Fig. 7A, after treatment with $\beta$-escin, the ratios of Bax/Bcl-2 were up-regulated in MG-63 cells. Specifically, 5 and $10 \mu \mathrm{M} \beta$-escin caused the $168 \%$ and $440 \%$ increases in the Bax/ Bcl-2 ratio, respectively, compared with that of the control group $(P<0.01)$.

\section{$\beta$-Escin inhibits tumour growth in MG-63-xenografted mice}

To determine whether $\beta$-escin could inhibit tumour growth in vivo, we further investigated the effects of $\beta$-escin on tumour growth in MG-63 xenografted mice. The results showed that $\beta$ escin treatment significantly reduced the tumour volume and weight in MG-63 xenografted nude mice (Fig. 9A and B, $P<0.01$ ). Furthermore, $\beta$-escin treatment significantly increased the apoptotic rates of tumour cells in the mice (Fig. 10B. $P<0.01$ ). 


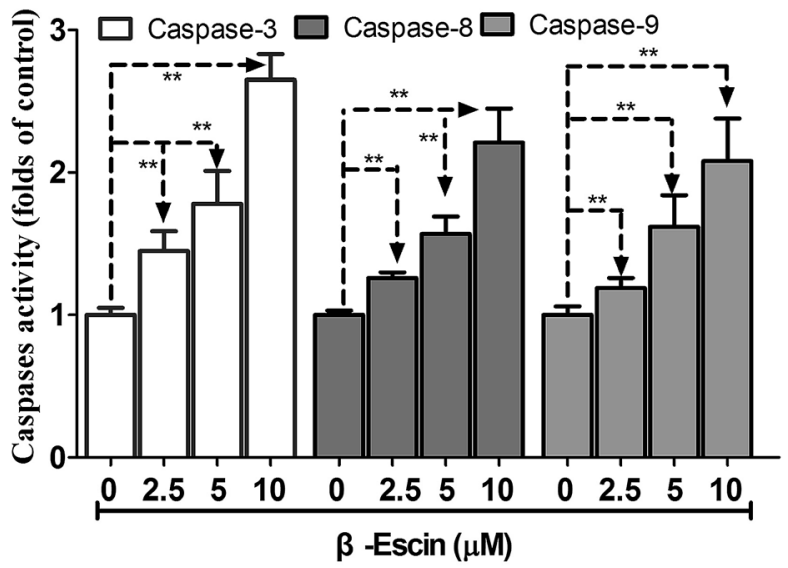

Fig. $6 \beta$-Escin induces activation of caspase-3, caspase- 8 and caspase- 9 in MG- 63 cells. MG- 63 cells were treated with $\beta$-escin for $48 \mathrm{~h}$, and then were lysed. Supernatants of the lysed cells were reacted with caspase substrates, and the levels of caspase-3, caspase- 8 and caspase- 9 activity were expressed as the chromophore absorbance at $405 \mathrm{~nm}$, which was determined by a microplate reader. Data were collected from three independent experiments. ${ }^{* *} P<0.01 \mathrm{vs}$. the group without $\beta$-escin treatment.
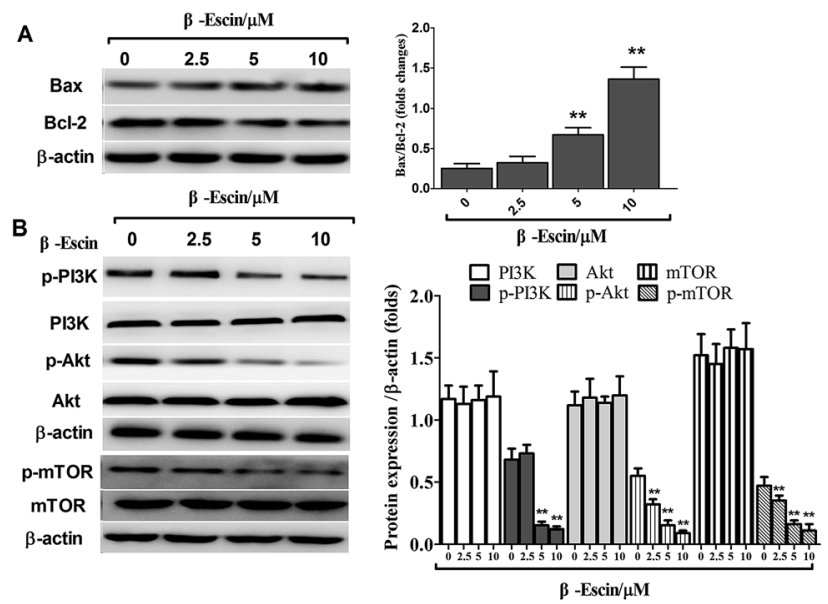

Fig. $7 \quad \beta$-Escin regulated $\mathrm{Bax}$ and $\mathrm{Bcl}-2$ expression and blocked the PI3K/Akt pathway in MG- 63 cells. (A) MG- 63 cells were treated with $\beta$ escin for $48 \mathrm{~h}$, and the levels of Bax and Bcl-2 were measured by western blotting. (B): MG-63 cells were treated with $\beta$-escin for $48 \mathrm{~h}$, and intracellular levels of PI3K, p-PI3K, Akt, p-Akt, mTOR and p-mTOR were analysed by western blotting. Data were collected from three independent experiments. ${ }^{* *} P<0.01$ vs. the group without $\beta$-escin treatment.

$\beta$-Escin blocks the PI3K/Akt pathway in MG-63 cells and MG63-transplanted nude mice

To elucidate the underlying anti-proliferative mechanism of $\beta$ escin, we evaluated the $\beta$-escin effects on the PI3K/Akt pathway in MG-63 cells. As seen in Fig. 7B, no obvious difference was observed in the expression of PI3K and Akt between the $\beta$-escin group and the control group $(P<0.01)$. Interestingly, we noticed that the levels of p-Akt, p-PI3K and p-mTOR in MG-63 cells were significantly decreased compared with the control $(P<0.01)$. To
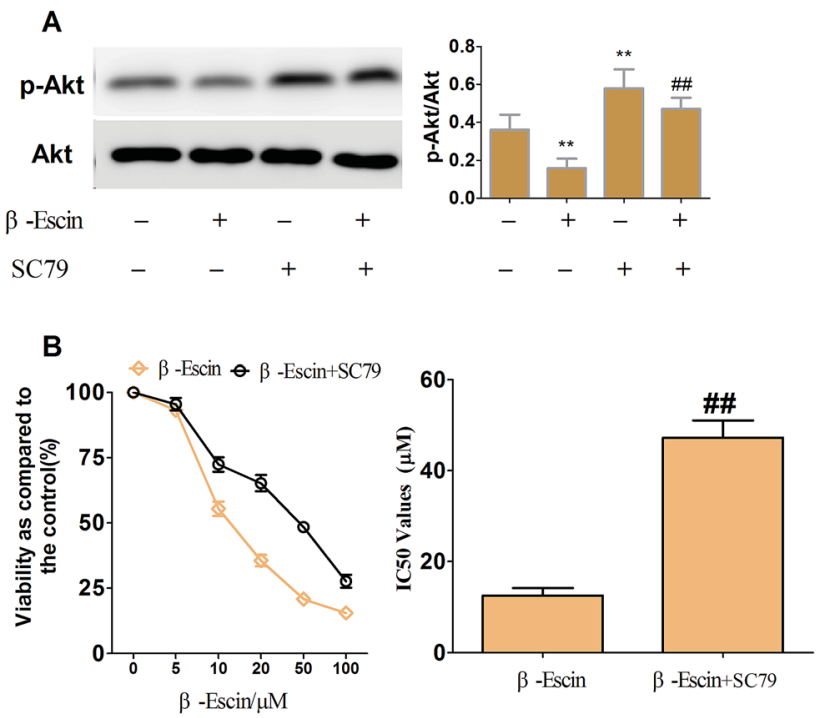

Fig. 8 SC79 reduced the $\beta$-escin-induced inhibitory effects on MG63 cell proliferation. MG- 63 cells were treated with $\beta$-escin in the presence (+) or the absence (-) of $20 \mu \mathrm{M} \mathrm{SC79} \mathrm{for} 48 \mathrm{~h}$, and then the cell viability was assayed by MTT. The expression of Akt and p-Akt was detected by western blotting. (A) Typical blot bands of target proteins were quantified. (B) SC79 increased the $\mathrm{IC}_{50}$ value of $\beta$-escin. Data were collected from three independent experiments. $* * P<0.01 \mathrm{vs}$. the group without $\beta$-escin and SC79 treatment. ${ }^{\#} P<0.01$ vs. the group of $\beta$-escin in the absence of SC79 treatment.

further characterize the role of the PI3K/Akt pathway in the antiproliferative effect exerted by $\beta$-escin, we used Akt activator SC79 to interfere with the action of $\beta$-escin. As seen in Fig. 8A and B, SC79 significantly increased p-Akt levels in MG-63 cells treated with $\beta$-escin and exerted an antagonistic effect to the anti-OS action of $\beta$-escin $(P<0.01)$. Moreover, we have also observed that oral administration of $\beta$-escin significantly reduced the expression of $\mathrm{p}$-Akt, $\mathrm{p}$-PI3K and $\mathrm{p}$-mTOR in the tumour tissues (Fig. 9C, Fig. 10A, $P<0.01$ ). Therefore, our data suggest that $\beta$-escin exerts its anti-OS activity by affecting the PI3K/Akt pathway.

\section{Discussion}

$\beta$-Escin is a well-known pentacyclic triterpenoid extracted from horse chestnut (Aesculus hippocastanum) seeds. In the present study, we showed that $\beta$-escin reduced the proliferation of OS cells in a dose- and time dependent manner. Moreover, we have also observed that $\beta$-escin exhibited anti-proliferative effects in an established OS xenografted mice model. The outcomes reported here are consistent with previous results. For instance, $\beta$ escin showed significant inhibitory effects on proliferation of hepatocellular carcinoma cells $\left(\mathrm{IC}_{50}: 65.7 \mu \mathrm{g} \mathrm{mL}{ }^{-1}\right) 12$, ovarian cancer cells $\left(\mathrm{IC}_{50}: 10.0 \mu \mathrm{g} \mathrm{mL} \mathrm{m}^{-1}\right)^{\mathbf{1 3}}$ and cholangiocarcinoma cells $\left(\mathrm{IC}_{50}\right.$ : $\left.33-63 \mu \mathrm{M}\right){ }^{14}$ Our results showed that $\mathrm{IC}_{50}$ values of $\beta$ escin ranged from 14.2 $\mu \mathrm{M}$ to $69.8 \mu \mathrm{M}$ in the tested OS cells. These data indicate that OS cells are highly sensitive to $\beta$-escin treatment and that $\beta$-escin is a promising anti-OS drug. Further experiments were performed to investigate a combined use of $\beta$ - 

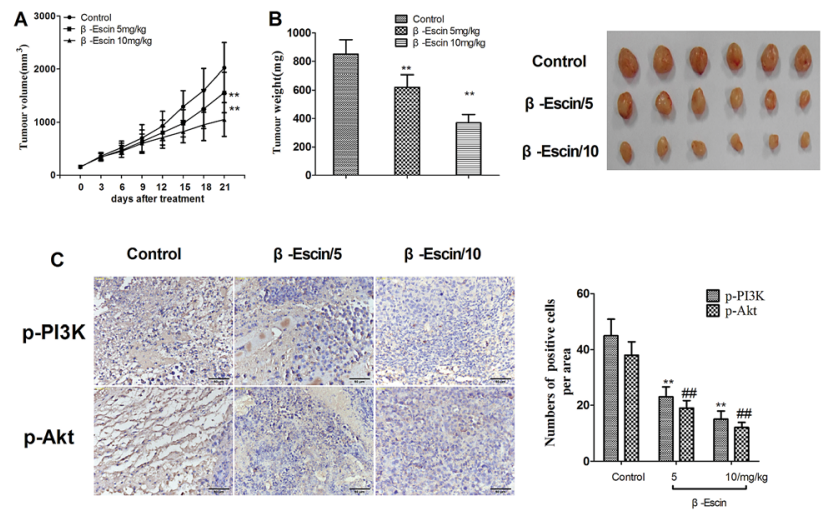

Fig. $9 \beta$-Escin effectively inhibited tumour growth in MG-63-transplanted nude mice. MG-63-transplanted nude mice were established and orally treated with $\beta$-escin for 3 weeks. The expression of $\mathrm{p}$-PI3K and $\mathrm{p}$-Akt in the tumour tissue was detected by immunohistochemical staining. (A) Tumour volume; (B) tumour weight; (C) the $p$-PI3K and $p$ Akt-positive cells in tumour tissue. Data are presented as the mean (M) \pm standard deviation (SD), $n=6,{ }^{* *} P<0.01$ or ${ }^{\# \#} P<0.01$ vs. the control group (the group without $\beta$-escin treatment)

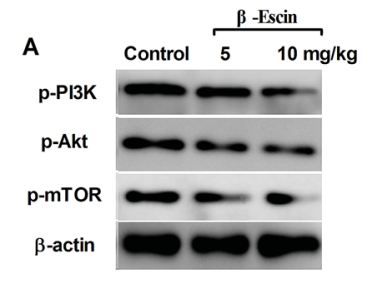

B

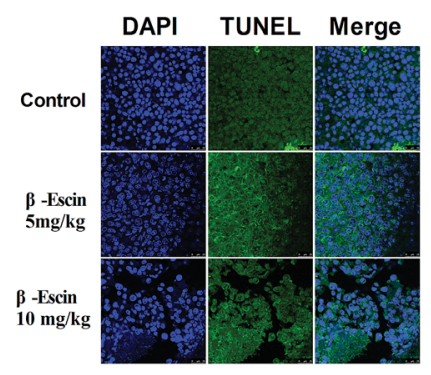

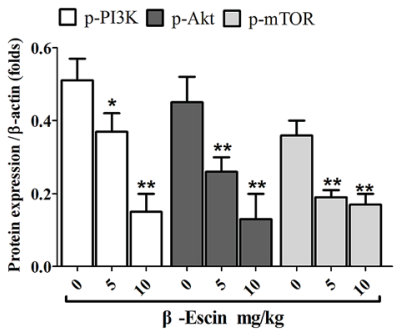

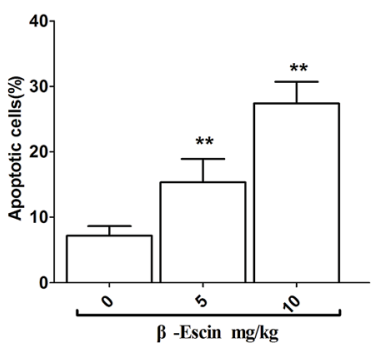

Fig. $10 \beta$-Escin promoted apoptotic death and blocked the PI3K/Akt pathway in the MG-63-transplanted nude mice. The levels of $p$-PI3K and $p$-Akt in the tumour tissue were detected by western blotting, and the apoptotic death was evaluated by the DAPI/TUNEL staining, which was visualized in a laser confocal microscope. (A) Typical blot bands of $\mathrm{p}$-PI3K, p-Akt and p-mTOR in the tumour tissues were quantified. (B) Apoptotic death in the tumour tissue was analysed by DAPI and TUNEL double-staining. Data are presented as the mean $(M) \pm$ standard deviation (SD), $n=6, * P<0.05, * * P<0.01$ vs. the control group (the group without $\beta$-escin treatment).

escin and commonly used anti-OS cytotoxic drugs. In the 1970s, chemotherapy started to be used for treating OS. ${ }^{20,21}$ Since then, combination chemotherapies have been introduced to enhance curative effects but caused significant side-effects, such as nausea, emesis, alopecia and myelosuppression. For example, it has been previously shown that most patients with high-grade OS experienced grade III-IV nausea, vomiting and haematologic toxicities after pre-operative combination chemotherapy with cisplatin and ADR. ${ }^{4} \beta$-Escin is a low-toxic compound. ${ }^{22}$ Previous in vitro studies reported ${ }^{\mathbf{1 6 , 2 3}}$ that the survival of normal prostate epithelial cell line was minimally affected by escin at a cytotoxic concentration $(24 \mu \mathrm{M})$ and that the survival of normal rat skeletal muscle cells was hardly influenced by escin at a high concentration $(50 \mu \mathrm{M})$. These reports imply that cytotoxic effects of $\beta$-escin have high selectivity between normal and cancer cells. In the present study, we first showed that the combined application of $\beta$-escin and anti-OS cytotoxic drugs (cisplatin, MTX, Dox or Ifos) synergistically inhibited proliferation of MG-63 or OS732 cells in vitro. We speculate that the main reasons are as following: first $\beta$-escin and chemotherapy possess beneficial effects in inhibiting OS cell proliferation based on their different molecular mechanisms; second, it is well known that P-glycoprotein is highly expressed in tumour cells, and pumps many anti-tumour drugs out of the cells to induce tumour resistance. ${ }^{24}$ In a previous study, $\beta$-escin $(5 \mu \mathrm{M}$ and $10 \mu \mathrm{M}$ ) has been reported to reduce the expression of Pglycoprotein in cholangiocarcinoma. ${ }^{25}$ Therefore, it is suggested that $\beta$-escin may have beneficial effects on absorption of the anti-OS cytotoxic drugs in the tumour cells, which results in enhanced anti-tumour effects. However, further research is required to test this possibility.

Apoptosis is one of the major mechanisms of cell death. It is well known that caspase signalling cascades control the process of apoptosis. Extrinsic and intrinsic cascades are triggered by caspase-8 and caspase-9, respectively. Caspase-8 activates downstream caspases and leads to apoptosis through the death receptor pathway, whereas activation of caspase- 9 further activates the executioner caspase- 3 and induces apoptosis through the mitochondrial pathway. ${ }^{26,27}$ The members of Bcl-2 family, such as Bcl-2 and Bcl-xl, regulate the mitochondrial apoptosis pathways by changing mitochondrial permeability. ${ }^{28} \beta$-Escinmediated apoptosis has been previously described in other cells. $^{12,19}$ Consistent with the previous results, our data revealed that $\beta$-escin promoted the apoptosis process both at the early and late stages as determined by FACS of Annexin V/PI-labelled cells. Moreover, we observed that $\beta$-escin significantly increased activities of caspase- 3 , caspase- 8 and caspase- 9 and simultaneously regulated the expression of Bax and $\mathrm{Bcl}-2$. The current findings are consistent with the previously published results for colon cancer cells, hepatocellular carcinoma cells and human cholangiocarcinoma cells. ${ }^{12,14,29}$ However, it should be noted that some cases of chemotherapy-mediated apoptosis differ from those found by us. For instance, the cisplatin-induced apoptosis in Hep-2 cells is via modulation of caspase-9 activity instead of caspase- $8,{ }^{30}$ and 5 -fluorouracil enhances activation of caspase-8 rather than of caspase-9 in SMMC-7721 cells. $^{\mathbf{1 2}}$ Therefore, our findings may explain why $\beta$-escin and chemotherapies showed synergistic inhibitory effects on the proliferation of OS cells.

The PI3K/Akt signalling pathway is well known for its key role in the cell proliferation and survival. Normally, PI3K generates PIP3 at plasma membrane, and PIP3 phosphorylates Akt to form p-Akt. Subsequently, p-Akt regulates expression of many molecules to affect cell proliferation and apoptosis. ${ }^{31}$ In OS, the PI3K/Akt pathway is deregulated in most cases of 
localized disease and in $100 \%$ cases of advanced-stage disease, ${ }^{32}$ which implies that alterations in this pathway may be a prerequisite for OS progression. Three reports ${ }^{33-35}$ have shown that p-Akt markedly increased c-Myc expression alongside an increase in the OS cell proliferation. Moreover, silencing miR223 increases protein levels of PI3k and p-Akt and promotes MG-63 cell proliferation, whereas knockdown of CXC chemokine receptor-7 inhibits proliferative activity of OS cells, partially through the decreased expression of PI3K and Akt. It has been previously confirmed that in the apoptotic process in OS cells increasing HSP70 expression leads to activation of PI3K/Akt, which partially prevents human OS cells from undergoing apoptosis. ${ }^{36}$ Furthermore, knockdown of Akt2 increases the apoptotic sensitivity of SAOS-2 cells in response to cisplatin treatment. ${ }^{37}$ Therefore, the PI3K/Akt pathway is a promising anti-OS therapeutic target. In previous studies, it has been concluded that $\beta$-escin chemosensitizes pancreatic cancer cells via deactivation of the nuclear factor-kappa B pathway $^{38}$ and induces apoptosis of hepatocellular carcinoma cells via down-regulation of the STAT3/JAK2 signalling pathway. ${ }^{39}$ In the present study, we found that $\beta$-escin effectively reduced expression of $\mathrm{p}-\mathrm{PI} 3 \mathrm{~K}, \mathrm{p}-\mathrm{Akt}$ and $\mathrm{p}-\mathrm{mTOR}$ both in vitro and vivo. Induction of Akt activation by SC79 exerted an antagonistic effect to the anti-OS effects of $\beta$-escin. Therefore, our results indicate that $\beta$-escin inhibits OS cell proliferation, at least in part, by inactivation of the PI3K/Akt pathway.

\section{Conclusions}

Taken together, in this study we found that $\beta$-escin inhibits proliferation of human OS cells in vitro and in vivo. Further work showed that $\beta$-escin blocked the PI3K/Akt pathway in MG-63 cells and MG-63 xenograft OS model. Our findings suggest that $\beta$-escin and cytotoxic drugs may be used together to treat OS patients.

\section{Conflicts of interest}

The authors report no conflicts of interest.

\section{References}

1 E. Cagliero, R. Ferracini, E. Morello, K. Scotlandi, M. C. Manara, P. Buracco, A. Comandone, R. Baroetto Parisi and N. Baldini, Reversal of multidrug-resistance using Valspodar (PSC 833) and doxorubicin in osteosarcoma, Oncol. Rep., 2004, 12, 1023-1031.

2 G. Ottaviani and N. Jaffe, The epidemiology of osteosarcoma, Cancer Treat. Res., 2009, 152, 3-13.

3 J. Chang, H. Wang, X. Wang, Y. Zhao, D. Zhao, C. Wang, Y. Li, Z. Yang, S. Lu, Q. Zeng, J. Zimmerman, Q. Shi, Y. Wang and Y. Yang, Molecular mechanisms of polyphyllin I-induced apoptosis and reversal of the epithelial-mesenchymal transition in human osteosarcoma cells, J. Ethnopharmacol., 2015, 170, 117-127.

4 S. Y. Rha, H. C. Chung, S. J. Gong, K. Y. Shim, J. B. Ahn, W. I. Yang, K. H. Shin, N. C. Yoo, J. H. Kim, J. K. Roh,
C. I. Lee and B. S. Kim, Combined pre-operative chemotherapy with intra-arterial cisplatin and continuous intravenous adriamycin for high grade osteosarcoma, Oncol. Rep., 1999, 6, 631-637.

$5 \mathrm{~K}$. Wilhelm and C. Feldmeier, Thermometric investigations about the efficacy of beta- escin to reduce postoperative edema (author's transl), Med. Klin., 1977, 72, 128-134.

6 D. Panigati, Pharmacology of escin, a saponin of Aesculus hippocastanum L. II. pharmacodynamics of escin, chapter II, Boll. Chim. Farm., 1992, 131, 284-293.

7 R. W. Frick, Three treatments for chronic venous insufficiency: escin, hydroxyethylrutoside, and Daflon, Angiology, 2000, 51, 197-205.

8 T. Wang, N. Jiang, B. Han, W. Liu, T. Liu, F. Fu and D. Zhao, Escin attenuates cerebral edema induced by acute omethoate poisoning, Toxicol. Mech. Methods, 2011, 21, 400-405.

9 H. Wang, L. Zhang, N. Jiang, Z. Wang, Y. Chong and F. Fu, Anti-inflammatory effects of escin are correlated with the glucocorticoid receptor/NF- $\mathrm{B}$ signaling pathway, but not the COX/PGF2 $\alpha$ signaling pathway, Exp. Ther. Med., 2013, 6, 419-422.

10 S. C. Gupta, A. K. Tyagi, P. Deshmukh-Taskar, M. Hinojosa, S. Prasad and B. B. Aggarwal, Downregulation of tumor necrosis factor and other proinflammatory biomarkers by polyphenols, Arch. Biochem. Biophys., 2014, 559, 91-99.

11 M. Li, C. Lu, L. Zhang, J. Zhang, Y. Du, S. Duan, T. Wang and F. Fu, Oral Administration of Escin Inhibits Acute Inflammation and Reduces Intestinal Mucosal Injury in Animal Models, J. Evidence-Based Complementary Altern. Med., 2015, 2015, 503617.

12 Z. J. Ming, Y. Hu, Y. H. Qiu, L. Cao and X. G. Zhang, Synergistic effects of beta-aescin and 5-fluorouracil in human hepatocellular carcinoma SMMC-7721 cells, Phytomedicine, 2010, 17, 575-580.

13 P. K. Chan, Acylation with diangeloyl groups at C21-22 positions in triterpenoid saponins is essential for cytotoxicity towards tumor cells, Biochem. Pharmacol., 2007, 73, 341-350.

14 D. Y. Shen, J. H. Kang, W. Song, W. Q. Zhang, W. G. Li, Y. Zhao and Q. X. Chen, Apoptosis of human cholangiocarcinoma cell lines induced by $\beta$-escin through mitochondrial caspase-dependent pathway, Phytother. Res., 2011, 25, 1519-1526.

15 Z. Zhang, J. Gao, X. Cai, Y. Zhao, Y. Wang, W. Lu, Z. Gu, S. Zhang and P. Cao, Escin sodium induces apoptosis of human acute leukemia Jurkat T cells, Phytother. Res., 2011, 25, 1747-1755.

16 S. Piao, M. Kang, Y. J. Lee, W. S. Choi, Y. S. Chun, C. Kwak and H. H. Kim, Cytotoxic effects of escin on human castration-resistant prostate cancer cells through the induction of apoptosis and G2/M cell cycle arrest, Urology, 2014, 84, 982e1-982e7.

17 H. S. Lee, J. E. Hong, E. J. Kim and S. H. Kim, Escin suppresses migration and invasion involving the alteration of CXCL16/CXCR6 axis in human gastric adenocarcinoma AGS cells, Nutr. Cancer, 2014, 66, 938-945. 
18 E. Seweryn, M. Gleńsk, K. Sroda-Pomianek, I. Ceremuga, M. Wlodarczyk and A. Gamian, Cytotoxic effects of four aescin types on human colon adenocarcinoma cell lines, Nat. Prod. Commun., 2014, 9, 387-390.

19 G. A. Çiftçi, A. Işcan and M. Kutlu, Escin reduces cell proliferation and induces apoptosis on glioma and lung adenocarcinoma cell lines, Cytotechnology, 2015, 67, 893904.

20 E. P. Cores, J. F. Holland, J. J. Wang and L. F. Sinks, Doxorubicin in disseminated osteosarcoma, J. Am. Med. Assoc., 1972, 221, 1132-1138.

21 M. Rozencweig, D. D. von Hoff, A. C. Louie and F. M. Muggia, Current trends and prospects in surgical adjuvant trials, Arch. Geschwulstforsch., 1978, 48, 673-679.

22 T. von Kreybig and K. Prechtel, Studies on toxicity and fertility of escin in the rat (author's transl), Arzneim. Forsch., 1977, 27, 1465-1466.

23 Y. W. Wang, S. J. Wang, Y. N. Zhou, S. H. Pan and B. Sun, Escin augments the efficacy of gemcitabine through downregulation of nuclear factor- $\kappa \mathrm{B}$ and nuclear factor- $\kappa \mathrm{B}$ regulated gene products in pancreatic cancer both in vitro and in vivo, J. Cancer Res. Clin. Oncol., 2012, 138, 785-797.

24 W. Li, H. Zhang, Y. G. Assaraf, K. Zhao, X. Xu, J. Xie, D. H. Yang and Z. S. Chen, Overcoming ABC transportermediated multidrug resistance: molecular mechanisms and novel therapeutic drug strategies, Drug Resist. Updates, 2016, 27, 14-29.

25 G. L. Huang, D. Y. Shen, C. F. Cai, Q. Y. Zhang, H. Y. Ren and Q. X. Chen, $\beta$-escin reverses multidrug resistance through inhibition of the GSK3 $\beta / \beta$-catenin pathway in cholangiocarcinoma, World J. Gastroenterol., 2015, 21, 1148-1157.

26 M. V. Fiandalo and N. Kyprianou, Caspase control: protagonists of cancer cell apoptosis, Exp. Oncol., 2012, 34, 165-175.

27 B. Kim, S. K. Srivastava and S. H. Kim, Caspase-9 as a therapeutic target for treating cancer, Expert Opin. Ther. Targets, 2015, 19, 113-127.

28 J. C. Reed, Proapoptotic multidomain Bcl-2/Bax-family proteins: mechanisms, physiological roles, and therapeutic opportunities, Cell Death Differ., 2006, 13, 1378-1386.

29 C. Zhao, Q. Zhang, T. Yu, S. Sun, W. Wang and G. Liu, Hypoxia promotes drug resistance in osteosarcoma cells via activating AMP-activated protein kinase (AMPK) signaling, J. Bone Oncol., 2016, 5, 22-29.

30 R. Kang, Z. H. Wang, B. Q. Wang, C. M. Zhang, W. Gao, Y. Feng, T. Bai, H. L. Zhang, P. H. Huang and S. X. Wen, Inhibition of autophagy-potentiated chemosensitivity to cisplatin in laryngeal cancer Hep-2 cells, Am. J. Otolaryngol., 2012, 33, 678-684.

31 H. Guo, P. German, S. Bai, S. Barnes, W. Guo, X. Qi, H. Lou, J. Liang, E. Jonasch, G. B. Mills and Z. Ding, The PI3K/AKT Pathway and Renal Cell Carcinoma, J. Genet. Genomics, 2015, 42, 343-353.

32 W. Zhou, M. Hao, X. Du, K. Chen, G. Wang and J. Yang, Advances in targeted therapy for osteosarcoma, Discov. Med., 2014, 17, 301-307.

33 G. Li, M. Cai, D. Fu, K. Chen, M. Sun, Z. Cai and B. Cheng, Heat shock protein 90B1 plays an oncogenic role and is a target of microRNA-223 in human osteosarcoma, Cell. Physiol. Biochem., 2012, 30, 1481-1490.

34 M. Zhai, L. Cong, Y. Han and G. Tu, CIP2A is overexpressed in osteosarcoma and regulates cell proliferation and invasion, Tumour Biol., 2014, 35, 1123-1128.

35 Y. Zhang, C. Q. Yang, Y. Gao, C. Wang, C. L. Zhang and X. H. Zhou, Knockdown of CXCR7 inhibits proliferation and invasion of osteosarcoma cells through inhibition of the PI3K/Akt and $\beta$-arrestin pathways, Oncol. Rep., 2014, 32, 965-972.

36 L. Ding, S. He and X. Sun, HSP70 desensitizes osteosarcoma cells to baicalein and protects cells from undergoing apoptosis, Apoptosis, 2014, 19, 1269-1280.

37 G. Zhang, M. Li, X. Zhu, Y. Bai and C. Yang, Knockdown of Akt sensitizes osteosarcoma cells to apoptosis induced by cisplatin treatment, Int. J. Mol. Sci., 2011, 12, 2994-3005.

38 A. Rimmon, A. Vexler, L. Berkovich, G. Earon, I. Ron and S. Lev-Ari, Escin Chemosensitizes Human Pancreatic Cancer Cells and Inhibits the Nuclear Factor- kappaB Signaling Pathway, Biochem. Res. Int., 2013, 2013, 251752.

39 S. M. Tan, F. Li, P. Rajendran, A. P. Kumar, K. M. Hui and G. Sethi, Identification of beta-escin as a novel inhibitor of signal transducer and activator of transcription 3/Janusactivated kinase 2 signaling pathway that suppresses proliferation and induces apoptosis in human hepatocellular carcinoma cells, J. Pharmacol. Exp. Ther., 2010, 334, 285-293. 